\title{
Deciphering mechanisms of staphylococcal biofilm evasion of host immunity
}

\author{
Mark L. Hanke and Tammy Kielian* \\ Department of Pathology and Microbiology, University of Nebraska Medical Center, Omaha, NE, USA
}

\section{Edited by:}

David Heinrichs, University of

Western Ontario, Canada

Reviewed by:

Jeffery A. Hobden, LSU Health

Sciences Center New Orleans, USA

Pietro Speziale, University degli

Studi di Pavia, Italy

${ }^{*}$ Correspondence:

Tammy Kielian, Department of

Pathology and Microbiology,

University of Nebraska Medical

Center, Omaha, NE 68198-5900

USA.

e-mail: tkielian@unmc.edu
Biofilms are adherent communities of bacteria contained within a complex matrix. Although host immune responses to planktonic staphylococcal species have been relatively well-characterized, less is known regarding immunity to staphylococcal biofilms and how they modulate anti-bacterial effector mechanisms when organized in this protective milieu. Previously, staphylococcal biofilms were thought to escape immune recognition on the basis of their chronic and indolent nature. Instead, we have proposed that staphylococcal biofilms skew the host immune response away from a proinflammatory bactericidal phenotype toward an anti-inflammatory, pro-fibrotic response that favors bacterial persistence. This possibility is supported by recent studies from our laboratory using a mouse model of catheter-associated biofilm infection, where S. aureus biofilms led to the accumulation of alternatively activated M2 macrophages that exhibit anti-inflammatory and pro-fibrotic properties. In addition, relatively few neutrophils were recruited into $S$. aureus biofilms, representing another mechanism that deviates from planktonic infections. However, it is important to recognize the diversity of biofilm infections, in that studies by others have demonstrated the induction of distinct immune responses during staphylococcal biofilm growth in other models, suggesting influences from the local tissue microenvironment. This review will discuss the immune defenses that staphylococcal biofilms evade as well as conceptual issues that remain to be resolved. An improved understanding of why the host immune response is unable to clear biofilm infections could lead to targeted therapies to reverse these defects and expedite biofilm clearance.

Keywords: S. aureus, S. epidermidis, biofilm, macrophage, neutrophil, immune evasion, alternative macrophage activation, fibrosis

\section{INTRODUCTION}

Biofilms are adherent communities of bacteria contained within a complex matrix. From a clinical standpoint, biofilm infections of native tissues or medical devices represent a serious therapeutic challenge, since organisms are typically recalcitrant to conventional antibiotics (Stewart and Costerton, 2001; Donlan and Costerton, 2002). Medical device-related infections are typified by high morbidity, with their clinical management often requiring device removal (Garvin and Hanssen, 1995; Morscher et al., 1995; Replacement et al., 1995; Lew and Waldvogel, 1997). In addition, despite prolonged therapy, the failure rate associated with infected devices is high, primarily due to their failure to be cleared by conventional antibiotics (Schoifet and Morrey, 1990; Wilson et al., 1990; Burger et al., 1991; Hartman et al., 1991; Rasul et al., 1991; Tsukayama et al., 1991; Brandt et al., 1997). To date, staphylococcal species remain one of the major causes of both health careassociated (HA) as well as community-associated (CA) infections. Staphylococcus epidermidis (S. epidermidis) is a frequent etiological agent of biofilm infections on medical devices, including indwelling catheters and prostheses (Fitzpatrick et al., 2005a; Otto, 2008; Fey, 2010), whereas Staphylococcus aureus (S. aureus) is commonly associated with tissue infections, such as endocarditis (Fitzsimmons et al., 2010) and osteomyelitis (Zuluaga et al.,
2006). With the emergence of drug-resistant strains in the 1960s, primarily methicillin-resistant $S$. aureus (MRSA), this ubiquitous pathogen is becoming an even greater therapeutic challenge. Consequently, based on their chronicity, debilitating nature, and economic impact, biofilm infections are of paramount significance in modern medicine. Therefore, it is imperative that we understand the mechanisms whereby staphylococcal biofilms alter immune recognition pathways to devise novel therapies for treating these devastating infections.

\section{STAPHYLOCOCCAL BIOFILMS AND TOLL-LIKE RECEPTORS (TLRs)}

Cells of the innate immune system recognize highly conserved pathogen-associated molecular patterns (PAMPs) that are expressed by large groups of microorganisms (Kawai and Akira, 2011). These conserved bacterial motifs are identified by a series of germ-line encoded receptors of the innate immune system termed pattern recognition receptors (PRRs). Toll-like receptors (TLRs) represent one PRR class expressed by cells of the innate immune system that mediate cellular activation in response to PAMPs (Kaisho and Akira, 2004; O'Neill, 2004). Thirteen TLRs have been described in the human and 10 in the mouse, each conferring responsiveness to various infectious agents as well as 
some endogenous ligands (Kopp and Medzhitov, 2003; Kawai and Akira, 2011). Staphylococcal species harbor a complex cell wall containing PAMPs that represent TLR2 ligands, namely lipoteichoic acid (LTA) and peptidoglycan (PGN) (Morath et al, 2002; Dziarski, 2003; Weber et al., 2003). PGN is released during normal bacterial growth as well as from dying organisms within staphylococcal biofilms (Mercier et al., 2002; Cerca et al., 2006; Moscoso et al., 2006; Qin et al., 2007; Strunk et al., 2010). Likewise, polysaccharide intercellular adhesin (PIA) and phenol-soluble modulin (PSM) expression in S. epidermidis promotes biofilm formation and can be recognized by TLR2 (Hajjar et al., 2001; Stevens et al., 2009). Staphylococcal lipoproteins (Lpp), a large family of membrane-anchored proteins, have also been identified as potent TLR2 ligands (Hashimoto et al., 2006a,b; Kurokawa et al., 2009). Some reports indicate that Lpp contaminating LTA and PGN preparations is responsible for most of the observed TLR2 stimulatory action (Travassos et al., 2004; Hashimoto et al., 2006a,b; Kurokawa et al., 2009). However, a synthetic LTA analog devoid of lipoproteins has also been shown to possess immune activity (Morath et al, 2002; Deininger et al., 2003). Regarding the role of PGN as a TLR2 agonist, a subsequent report demonstrated that the solubility characteristics of purified PGN dictated whether it was capable of triggering TLR2 (Dziarski and Gupta, 2005). Importantly, the ability of PGN to activate TLR2 can be destroyed by certain purification methods, leading to discrepancies in potency for TLR2 activation. Therefore, the immunostimulatory role of LTA and the innate immune receptor specificity of staphylococcal PGN for TLR2 remains an issue of debate. TLR9 is an intracellular receptor that recognizes unmethylated $\mathrm{CpG}$ motifs characteristic of bacterial DNA (Hemmi et al., 2000; Bauer et al., 2001). Mammalian DNA is methylated on guanine residues, which serves as a critical self vs. non-self discriminator. Upon phagocytosis and digestion of bacteria in the phagosome, bacterial DNA is liberated and engages TLR9. However, it is well recognized that extracellular DNA (eDNA) can also trigger TLR9dependent activation, which is relevant to biofilms due to the extensive amount of eDNA within the matrix (Whitchurch et al., 2002; Allesen-Holm et al., 2006; Rice et al., 2007). Innate immune cells, including macrophages, neutrophils (PMNs), and dendritic cells, express TLR2 and TLR9 and are competent to respond to both Lpp/PGN/LTA and eDNA, respectively, which culminates in the induction of a wide array of classical pro-inflammatory mediators and bactericidal activity (Takeuchi et al., 1999; Bauer et al., 2001; Hertz et al., 2001; Jones et al., 2001; Kirschning and Schumann, 2002; Hayashi et al., 2003).

The role for TLRs in mediating innate immune recognition of staphylococcal species during planktonic growth has been well-characterized (Yoshimura et al., 1999; Takeuchi et al., 2000; Mullaly and Kubes, 2006; Stevens et al., 2009; Strunk et al., 2010). However, recent reports have determined that one mechanism utilized by biofilms to evade host immunity is by circumventing TLR2 and TLR9 recognition (Figure 1) (Bernthal et al., 2011; Thurlow et al., 2011). This agrees with the finding that patients bearing mutations which inactivate TLR2 have no increased risk of developing post-arthoplasty S. aureus infections (El-Helou et al., 2011). In contrast, the ability of S. aureus biofilms to evade TLR9 recognition differs from $P$. aeruginosa biofilms, since eDNA has been demonstrated to be a major proinflammatory stimulus during $P$. aeruginosa biofilm growth (Fuxman Bass et al., 2010). This emphasizes the importance of bacterial species and growth state in dictating whether innate immune sensor mechanisms will be effective at clearing infection. It is also possible that $S$. aureus biofilms may be recognized by alternative PRRs besides TLR2 or TLR9. For example, eDNA could also be sensed by other intracellular PRRs such as AIM2 or DNA-dependent activator of IFN-regulatory factors (DAI) (Vilaysane and Muruve, 2009; Hornung and Latz, 2010). In addition, the degradation product of staphylococcal PGN, muramyl dipeptide, can be sensed by the cytoplasmic PRR nucleotide-binding oligomerization domain-containing protein 2 (NOD2) to elicit proinflammatory mediator release (Girardin et al., 2003; Volz et al., 2010). The mechanism(s) responsible for TLR2/TLR9 evasion by S. aureus biofilms are not known but could also be explained by ligand inaccessibility. Biofilms are encased within a complex three-dimensional structure with few free bacteria exposed at the outer surface, thus avoiding detection by PRRs expressed on the surface of phagocytes (Thurlow et al., 2011). Likewise, complex polysaccharide polymers that are known components of the biofilm matrix (Flemming and Wingender, 2010), may interfere with optimal engagement of potential ligands with TLRs. Understanding the receptor repertoire triggered by staphylococcal biofilms may enable the selective targeting of these molecules to facilitate pathogen elimination and/or render the biofilm more sensitive to conventional antibiotic therapies.

\section{ROLE FOR INTERLEUKIN-1 $\beta$ (IL-1 $\beta$ ) AND OTHER MYD88-DEPENDENT PATHWAYS IN IMMUNE RECOGNITION OF STAPHYLOCOCCAL BIOFILMS}

In contrast to a lack of TLR2 and TLR9 involvement during staphylococcal biofilm infections, a recent report has revealed a role for IL-1 $\beta$ in controlling early bacterial burdens in a postarthroplasty S. aureus biofilm infection model (Bernthal et al., 2011). Specifically, biofilm formation was enhanced in IL-1 $\beta$ KO mice concomitant with decreased PMN recruitment; however, PMN infiltrates were visualized by H\&E staining in this study and quantitative assessment by flow cytometry was not performed. It is worth noting that PMN influx is minimal in a model of s.c. catheter-associated S. aureus biofilm infection (Figure 2), which may represent differences in the biofilm locale or degree of planktonic infection surrounding the biofilm. Studies from our laboratory have recently investigated the role of myeloid differentiation factor 88 (MyD88), the common downstream adaptor utilized by both the IL-1 receptor (IL-1R) and TLRs (Hanke and Kielian, in revision), in regulating S. aureus biofilm growth. MyD88 signaling culminates in NF- $\kappa B$-mediated transcription and until our work, nothing was known regarding the role of MyD88- or NF- $\mathrm{KB}$-dependent signaling during staphylococcal biofilm infections. Utilizing a well-characterized model of catheter-associated S. aureus biofilm infection (Rupp et al., 1999; Cassat et al., 2007; Thurlow et al., 2011), MyD88 KO mice displayed significant increases in bacterial burdens on catheters as well as surrounding tissues throughout the course of infection compared to WT animals. Additionally, S. aureus titers 


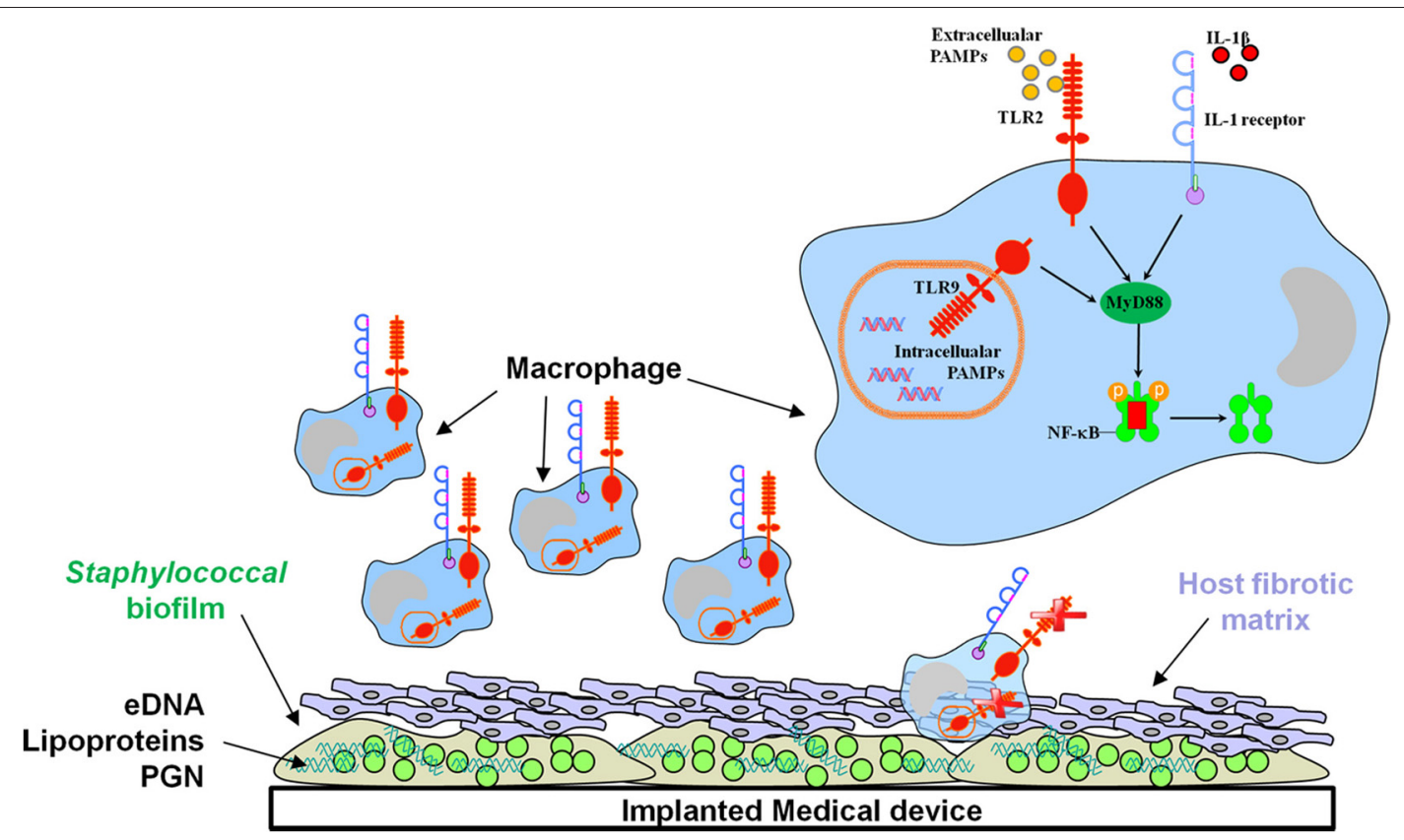

FIGURE 1 | The signaling adaptor MyD88 is pivotal for regulating biofilm development. Recent studies have revealed important roles for $\mathrm{IL}-1 \beta$ and MyD88-dependent pathways in controlling bacterial burdens during $S$. aureus biofilm growth, whereas biofilms evade TLR2/TLR9 recognition. The macrophage is a major cellular infiltrate during device-associated biofilm infections; however, current evidence indicates that macrophage microbicidal properties are inhibited by the biofilm.

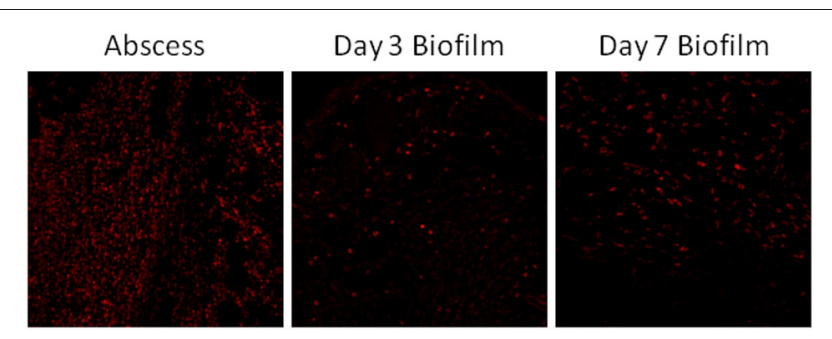

FIGURE 2 | Neutrophil recruitment into $\boldsymbol{S}$. aureus biofilms in vivo is limited. C57BL/ 6 mice were infected with $5 \times 10^{5}$ CFU USA300 LAC either in the lumen of surgically implanted catheters or s.c. in the absence of any indwelling device to establish biofilm and abscess infections, respectively. Animals were sacrificed at days 3 or 7 following $S$. aureus exposure, whereupon tissues surrounding infected catheters or s.c. injection sites were collected and subjected to immunofluorescence staining for the neutrophil-specific marker Ly-6G (red) and visualized by confocal microscopy (original magnification $\times 20$ ).

were significantly elevated in the heart and kidney of MyD88 KO mice, demonstrating a role for MyD88 in bacterial containment at the site of biofilm infection. Furthermore, immunofluorescence staining revealed an increased fibrotic response associated with biofilms in MyD88 KO animals, which coincided with increased recruitment of alternatively activated M2 macrophages (Hanke and Kielian, in revision). Collectively, these studies reveal a role for IL-1 $\beta$, potentially mediated through MyD88 signaling, in S. aureus biofilm containment (Figure 1). Although it is evident that these pathways influence biofilm development, they are not sufficient to eradicate staphylococcal biofilms, since these infections persist in an immunocompetent host. Instead, tonic
MyD88/IL-1 $\beta$ action could account for the finding that biofilm burdens remain relatively constant throughout the course of infection (Thurlow et al., 2011), which likely represents an equilibrium between bacterial dispersal from the biofilm, clearance of planktonic organisms (presumably via MyD88/IL-1 $\beta$ pathways), and continued biofilm growth.

Although it is clear that IL-1 $\beta$ and MyD88-dependent pathways can influence $S$. aureus biofilm development, the precise molecular pathways remain to be defined. In particular, numerous receptors utilize MyD88, including multiple TLRs, IL-1R, IL-18R, and IL-33R and it is uncertain which is most relevant or alternatively, if multiple pathways are triggered and act in an additive/synergistic manner. Based on the findings with IL$1 \beta$-deficient mice (Bernthal et al., 2011), it is likely that IL-1RI signaling plays a key role, but this remains to be determined. Importantly, IL-1 $\beta$ is produced as an inactive precursor that requires proteolytic cleavage for its release. This process requires the coordinate induction of a two-signal model mediated by TLRs (signal 1) and Nod-like receptors (NLR; signal 2), the latter of which forms the inflammasome that is responsible for processing the inactive forms of IL- $1 \beta$ and IL-18 into their mature states (Craven et al., 2009; Schroder and Tschopp, 2010). Signal 1 is elicited by TLR signaling though MyD88 that triggers the transcriptional induction of pro-IL-1 $\beta$ and pro-IL-18, which remain inactive until a second signal is initiated. Signal 2 has been shown to originate within the host cell cytoplasm and is mediated by the sensing of a danger signal by members of the NLR family of intracellular PRRs. With regard to staphylococcal infections, signal 2 can be triggered by intact bacteria or purified $\alpha$ - and $\gamma$-hemolysins, which lead to $\mathrm{K}^{+}$efflux from the cell (Craven 
et al., 2009; Hanamsagar et al., 2011). Currently, we know nothing about what receptors upstream of MyD88 are required for staphylococcal biofilm recognition or signals that lead to IL-1 $\beta$ transcription or proteolytic processing. These issues will be important to evaluate in the quest to unveil promising therapeutic targets for staphylococcal biofilm eradication.

Signals emanating from TLRs, IL-1R, and numerous cytokine receptors trigger activation of the transcription factor NF- $\kappa \mathrm{B}$. The NF- $\mathrm{B}$ family regulates the expression of numerous genes associated with proliferation, differentiation, and cell death, as well as innate and adaptive immune responses, which represents an attractive target for exploitation by staphylococcal species (Rahman and McFadden, 2011). Indeed, NF- $\kappa$ B signaling is the most frequent intracellular pathway targeted by numerous microbes to subvert the immune response (Finlay and McFadden, 2006). S. epidermidis PIA-, accumulation-associated protein (Aap)-, or extracellular matrix-binding protein (Embp)dependent biofilms were protected from macrophage phagocytic uptake and induced minimal NF- $\kappa \mathrm{B}$ activation and IL- $1 \beta$ production (Schommer et al., 2011). Interestingly, similar to our previous results where physical disruption of the biofilm structure allowed for macrophage phagocytosis, mechanical dispersal of $S$. epidermidis biofilms partially restored NF-кB activation (Schommer et al., 2011; Thurlow et al., 2011). Together, these results indicate that staphylococcal biofilms possess mechanisms to circumvent macrophage phagocytic uptake and limit proinflammatory activity by attenuating NF- $\kappa$ B activity.

Another study has shown that inflammatory cytokines were augmented during early $S$. aureus biofilm infection, whereas antiinflammatory infiltrates predominated later. Based on these findings, the authors proposed that the acute inflammatory response induced tissue damage to facilitate biofilm growth (Prabhakara et al., 2011). However, the infectious inoculum utilized was rather high and the implanted device was coated with bacteria prior to surgical implantation, which might account for the initial proinflammatory response if a significant degree of planktonic organisms were present prior to mature biofilm formation. Since it takes time for biofilm maturation to occur, the antiinflammatory response that was reported at later time points might be a better indication of the immune response to a mature biofilm, which is supported by other studies (Prabhakara et al., 2011; Thurlow et al., 2011). However, differences in the sites of biofilm infection, methods of inoculating foreign devices (i.e., infecting devices prior to insertion or inoculation directly into the implanted device in vivo), and infectious inoculums may influence the nature of the host immune response to staphylococcal biofilms. The relative impact of each of these factors remains to be determined.

\section{ANTIMICROBIAL PEPTIDES AND STAPHYLOCOCCAL BIOFILMS}

The innate immune response to numerous microbial infections, including staphylococcal species, is mediated, in part, by pre-existing soluble factors that recognize and destroy pathogens or target them for killing by macrophages and PMNs. Two examples are antimicrobial peptides (AMPs) and the complement pathway Medzhitov and Janeway, 2000; Medzhitov, 2007, both of which are induced immediately following infection and represent a first line of defense against invading microbes. The complement system consists of blood-derived proteins that are activated in an enzymatic cascade to eliminate pathogens from the host. PMN killing of planktonic S. epidermidis is complementdependent and biofilm formation has been shown to trigger complement activation in a PIA-dependent manner (Clark and Easmon, 1986; Kristian et al., 2008; Fredheim et al., 2011). However, S. epidermidis biofilms impair IgG and complement deposition, resulting in increased resistance to opsonization and phagocyte-mediated killing (Kristian et al., 2008; Fredheim et al., 2011). AMPs are universal innate defense molecules in humans and other higher organisms, which despite co-evolution with bacteria have retained their efficacy, as bacteria have yet to develop wide-spread resistance. These peptides show narrow or broadspectrum activity against bacteria, fungi, viruses, and/or parasites. The net-positive charge, amphipathicity, and small size of AMPs allow for the disruption of microbial membranes and also inhibit cell wall, nucleic acid, and protein biosynthesis (Yeaman and Yount, 2003; Brogden, 2005). Currently, only a few AMPs have shown efficacy against $S$. aureus biofilms by either inhibiting biofilm formation or down regulating the expression of genes involved in biofilm development (Lopez-Leban et al., 2010; Dean et al., 2011). Recent collaborative studies from our laboratory have identified a synthetic AMP, DASamP1, that selectively kills MRSA and prevents biofilm formation in vivo (Menousek et al., 2012). Although AMPs have not been extensively explored for their anti-biofilm activity, these initial studies suggest that this class of antimicrobials deserves attention and could conceivably exert additive/synergistic effects with other approaches for the treatment of staphylococcal biofilm infections.

\section{INNATE CELLULAR IMMUNITY}

To date, most studies investigating innate immune responses to biofilms have been performed with $P$. aeruginosa and $S$. epidermidis, where PMNs have been shown to phagocytose biofilmassociated bacteria and produce oxidative bursts, albeit at reduced levels compared to planktonic bacteria (Jensen et al., 1990; Jesaitis et al., 2003; Walker et al., 2005; Chandra et al., 2007; Kristian et al., 2008; Graves et al., 2010). Neutrophils represent a first line of cellular defense against bacterial infections and possess a potent arsenal of bactericidal compounds, including defensins, cathelicidins, and lysozyme (Nathan, 2006; Nauseef, 2007). In terms of their bactericidal activity, PMNs are most notable for their ability to produce large amounts of reactive oxygen intermediates (ROI) catalyzed by NADPH oxidase. In addition to ROI production, PMNs can also secrete several proinflammatory cytokines, including TNF- $\alpha$ and IL- $1 \beta$ as well as chemokines, such as CXCL2 (macrophage inflammatory protein-2; MIP-2) and CXCL1 (KC, keratinocyte-derived chemokine; both are functional mouse homologs of IL-8) and CCL3 (MIP-1 $\beta$ ) (Cassatella, 1995; Witko-Sarsat et al., 2000; Nathan, 2006). Although PMNs exert $S$. aureus bactericidal activity under planktonic conditions (Fournier and Philpott, 2005; Graham et al., 2007), the direct role of these cells in modulating $S$. aureus biofilm growth has not yet been examined. Although a previous report had suggested that PMNs were competent to invade a $S$. aureus biofilm, this study 
was performed with peripheral blood leukocytes that represented a mixed cell population of PMNs, monocytes, and T and B lymphocytes (Leid et al., 2002). Therefore, the dynamics of PMN interactions with biofilms could not be definitively determined. Interestingly, this study also detected mammalian cytokine production in biofilm-conditioned supernatants, which may be explained by interference of $S$. aureus protein A, a MSCRAMM that binds the Fc portion of immunoglobulins, non-specifically binding to capture/detection antibodies in the ELISA assay. More recent studies using 85-95\% pure PMN populations suggested that both $S$. aureus and $S$. epidermidis biofilms are phagocytosed by PMNs albeit to different extents, with $S$. aureus being more susceptible to phagocytic uptake (Günther et al., 2009; Graves et al., 2010; Meyle et al., 2010). However, it is important to note that these studies evaluated immature $S$. aureus biofilms grown under what might be considered sub-optimal conditions, such as continuous shaking and on non-coated surfaces (Wagner et al., 2011). Therefore, the thickness and complexity (i.e., presence of secondary tower structures) of biofilms should be considered when assessing the degree of phagocytosis by various immune cell populations.

As previously mentioned, PMN infiltrates were reduced during post-arthroplasty $S$. aureus biofilm infection in IL- $1 \beta$ deficient mice; however, the functional importance of PMNs in controlling bacterial burdens was not explored in this report (Bernthal et al., 2011). Future studies with neutrophil-depleted mice will provide definitive evidence regarding the role of PMNs in biofilm clearance in models where significant infiltrates are observed. Likewise, potential bystander damage originating from the cytotoxic, proteolytic, and proinflammatory effector functions of PMNs in tissue degradation and osteolysis should also be examined. A recent study reported a prominent leukocyte infiltrate associated with post-traumatic osteomyelitis, which consisted predominantly of activated PMNs. The authors proposed that during the ineffective "frustrated" attempt to phagocytose bacteria, PMNs release cytotoxic and proteolytic molecules that, in turn, amplify tissue injury in conjunction with biofilm-derived toxins and proteolytic enzymes (Wagner et al., 2003, 2005). As mentioned earlier, PMN recruitment is minimal in a different model of $S$. aureus biofilm infection (Figure 2), and instead macrophage infiltrates predominate (Thurlow et al., 2011). The reasons responsible for differential PMN recruitment in various biofilm models may be influenced by the extent of tissue vascularization, maturity, and extent of biofilm development, and whether the inoculum used to establish biofilm formation may lead to an initial planktonic component that results in early PMN recruitment that is independent of the developing biofilm. The latter point is particularly relevant, since it is reasonable to assume that not all organisms will attach to an artificial device when introducing bacteria adjacent to the implant. In addition, larger inoculums may result in more planktonic bacteria neighboring the device, which are known to elicit a robust proinflammatory response, and conceivably augment PMN infiltrates. In contrast, in the context of lower inoculums, even if some organisms do not attach, the small number of planktonic bacteria would not be expected to elicit a robust inflammatory response. In addition, it could be argued that low inoculums more accurately mimic the events that would be encountered during native device seeding in vivo. Another factor to consider is the type of device studied. In the case of a hollow catheter, bacteria introduced directly into the lumen may be afforded additional protection from immune recognition by shielding provided by the catheter wall. In the case of a solid device, bacteria are immediately exposed to host tissues, in theory enabling an immediate proinflammatory response. Regardless, these issues should become clearer as additional in vivo studies examining staphylococcal biofilm pathogenesis are performed.

Several studies investigating innate immunity to staphylococcal species have focused on PMNs (Kobayashi et al., 2003; Anwar et al., 2009; Graves et al., 2010), whereas macrophage responses have received relatively less attention. Although PMNs are important antimicrobial effectors, their transcriptional capacity is limited, and their short lifespan requires constant recruitment into infection sites (Yamashiro et al., 2001; Borregaard, 2010; Mantovani et al., 2011). In contrast, resident macrophages are present in virtually all host tissues and represent a critical antimicrobial effector population and immediate line of defense against microbial invasion (Serbina et al., 2008; Gonzalez-Mejia and Doseff, 2009). Macrophages are more long-lived compared to PMNs and produce numerous proinflammatory mediators that are critical for immune cell recruitment and activation (Silva, 2010, 2011). In addition, macrophages possess potent phagocytic capacity and, like PMNs, can produce ROI and RNI species. However, macrophages are a major source of pro-inflammatory cytokines and chemokines, since activated cells survive significantly longer compared to PMNs (Furze and Rankin, 2008).

Examination of several proinflammatory signals responsible for macrophage and PMN recruitment (CCL2 and CXCL2, respectively) and activation (TNF- $\alpha$ and IL-1 $\beta$ ) were significantly reduced in $S$. aureus biofilm infected tissues (Thurlow et al., 2011). Of note, the disconnect between reduced CCL2 levels and prominent macrophage infiltrates during biofilm formation indicate that existence of alternative macrophage chemoattractant signals, the identity of which remains unknown. Inducible nitric oxide synthase (iNOS) expression was also decreased, whereas arginase-1, a key enzyme involved in the collagen biosynthetic pathway was increased in macrophages surrounding the biofilm. Because both iNOS and arginase-1 compete for arginine to initiate their respective biosynthetic pathways, the preferential induction of arginase-1 expression in biofilm-associated macrophages likely results in skewing the immune response away from bacterial killing to favor fibrosis (Thurlow et al., 2011). Indeed, this possibility appears plausible based on three pieces of evidence. First, biofilm-associated device infections in animal models as well as humans are typified by a robust fibrotic response (Pickering et al., 1989; Buret et al., 1991; Duch and Yee, 2001), which might inadvertently serve to further sequester the biofilm from immune recognition. Second, in vitro and in vivo studies from our laboratory demonstrate that $S$. aureus biofilms skew macrophages toward an anti-inflammatory M2 phenotype (Thurlow et al., 2011), which contributes to fibrosis. Likewise, S. epidermidis biofilms with higher proportions of viable, but non-culturable dormant bacteria have recently been shown to induce less macrophage activation as revealed 
by reduced pro-inflammatory cytokine production in vitro and expression of surface activation markers in vivo (Cerca et al., 2011). Third, various ECM molecules have been shown to attenuate immune cell proinflammatory activity, in accordance with a wound healing environment (Adair-Kirk and Senior, 2008; Korpos et al., 2009; Rodero and Khosrotehrani, 2010; Sorokin, 2010; Mahdavian Delavary et al., 2011; Wight and Potter-Perigo, 2011). Based on these observations, we propose that staphylococcal biofilms skew the host innate immune response from a classical pro-inflammatory bactericidal phenotype toward an anti-inflammatory, pro-fibrotic response to favor bacterial persistence (Figure 3). The typical response of macrophages to bacterial infections involves the induction of genes related to proinflammatory M1 polarization that is usually associated with protection during acute infections. However, a growing number of studies demonstrate that some organisms have evolved sophisticated strategies to interfere with M1 polarization by either inhibiting macrophage microbicidal activity (Vazquez-Torres et al., 2000), hindering M1 cytokine expression/secretion (Bost and Clements, 1997; Dornand et al., 2002), or by producing virulence factors that directly impede NF-кB activation (Pathak et al., 2007). In contrast, bacterial persistence is often linked to macrophage reprogramming toward an anti-inflammatory M2 state (reviewed in Benoit et al., 2008). Additional studies are warranted to tease apart this relationship from a mechanistic perspective.

Although we and others have previously demonstrated that PMNs are capable of phagocytosing S. aureus biofilms (Günther et al., 2009; Graves et al., 2010; Thurlow et al., 2011), macrophages are limited in their ability to ingest $S$. aureus when organized within a biofilm compared to planktonic bacteria (Thurlow et al., 2011). Importantly, macrophages were capable of phagocytosing

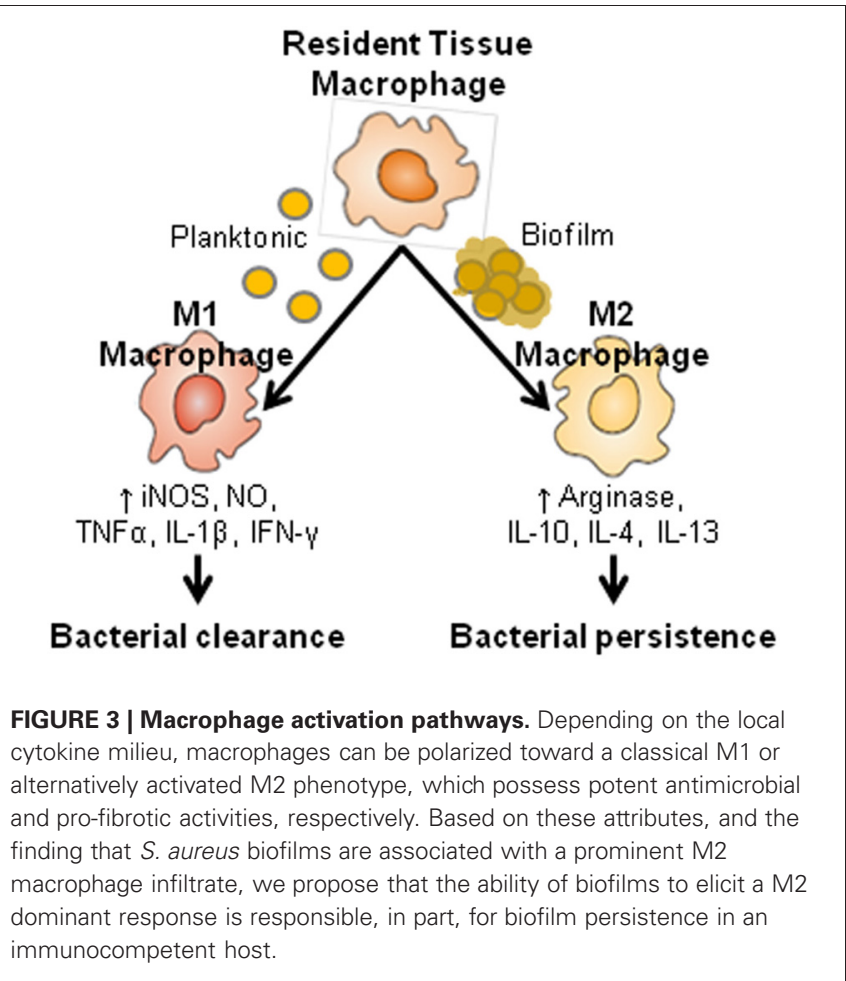

bacteria from mechanically disrupted biofilms, suggesting either (1) the failure to physically engulf the complex biofilm structure that exceeds the size of a macrophage by several orders of magnitude, or (2) inability opsonize intact biofilms. The latter is supported by a previous study showing that IgG and $\mathrm{C} 3 \mathrm{~b}$ deposition is reduced on the surface of $S$. epidermidis biofilms compared with planktonic bacteria (Kristian et al., 2008). Interestingly, macrophages incubated with conditioned supernatants from $S$. aureus biofilms in vitro were unable to phagocytize latex beads or planktonic bacteria, which were readily internalized by untreated macrophages (Figure 4). Consequently, it appears that biofilms not only alter macrophage activation states, but also paralyze their phagocytic potential in response to particulate material that would be readily internalized under normal conditions. The implications of this phenomenon during biofilm infections are envisioned to be significant, in that macrophages would be impaired in their ability to scavenge dead cells/debris or contribute to tissue remodeling in the vicinity of the biofilm. Although these possibilities remain speculative, they could conceivably contribute to biofilm persistence in vivo.

The majority of macrophages that invaded S. aureus biofilms in vitro were dead compared to those that remained above the biofilm surface (Thurlow et al., 2011). There are a number of potential mechanisms that may account for the differential sensitivity of macrophages to cell death based on their physical distance from the biofilm, which can be framed in the context of metabolic "layers" that have been proposed for the biofilm (Spormann, 2008; Stewart and Franklin, 2008; Bester et al., 2010). These zones represent a complex relationship between anaerobic and aerobic microenvironments within the biofilm mass, bacterial-influenced fluctuations in $\mathrm{pH}$, and bacterial metabolic profiles that may affect macrophage survival due to the release of toxic byproducts. Furthermore, the biofilm proper may contain a high concentration of lytic toxins, which in combination with the bulky biofilm matrix may lead to frustrated phagocytosis and cell death (Hoiby et al., 1995; Costerton et al., 1999). Additional studies are warranted to investigate the factor(s) that are responsible for innate immune cell death upon contact with staphylococcal biofilms.
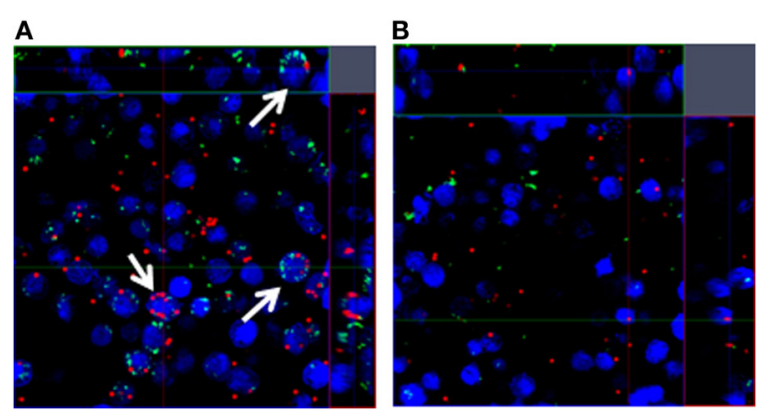

FIGURE 4 | Phagocytosis is impaired in response to $\boldsymbol{S}$. aureus biofilms. Bone marrow-derived macrophages labeled with CellTracker Blue (blue) were incubated with (A) fresh medium or (B) biofilm-conditioned supernatants for $2 \mathrm{~h}$, whereupon planktonic $S$. aureus expressing GFP (green) and fluorescent latex beads (red) were added for $1 \mathrm{~h}$ to determine macrophage phagocytic ability by confocal microscopy. Arrows indicate phagocytic macrophages. 


\section{FIBROSIS}

Biofilm infections typically become surrounded by a fibrous capsule that is likely driven by host pro-fibrotic pathways (Pickering et al., 1989; Buret et al., 1991; Duch and Yee, 2001). However, little information is available regarding the host-derived factors that trigger biofilm encapsulation or its consequences on the evolving immune response. Although it is presumed that biofilm encapsulation by the host represents a protective response to contain the infection, this process may inadvertently provide survival advantages to the bacteria. For example, despite an early macrophage infiltrate, immunofluorescence staining demonstrated that the majority of cells remained distant from the infection site, with only a few macrophages recruited to the biofilm surface (Thurlow et al., 2011). Therefore, the fibrotic capsule may provide a protective barrier to physically sequester invading immune cells from the biofilm and/or limit antibiotic penetration into the infection site (Xu et al., 2000; Singh et al., 2010). Alternatively, fibrosis may enable the dissemination of S. aureus when organisms are released from the biofilm through their ability to produce proteases and adhesion molecules that demonstrate affinity for host fibrotic molecules (Gordon and Lowy, 2008). What remains unknown is whether encapsulation is triggered by virulence factor(s) released from the biofilm and the consequences of fibrosis formation.

The host immune response plays a critical role during both physiological and pathological fibrosis by releasing several profibrotic cytokines and other molecules that participate in extracellular matrix (ECM) remodeling to induce fibrosis (Mauviel, 2005; Lupher and Gallatin, 2006; Wynn, 2008). Fibrosis has been linked to the transition of macrophages into an alternatively activated M2 phenotype, which is dictated, in part, by the pro-fibrotic Th2 cytokines IL-4, IL-5, and IL-13 (Wynn, 2004; Lupher and Gallatin, 2006). Recent studies suggest that certain pathogens favor the transition of the immune response from a classical pro-inflammatory to an anti-inflammatory state (Bouhlel et al., 2007; Gallardo-Soler et al., 2008). Since fibrosis typically ensues following the dampening of inflammation (Lupher and Gallatin, 2006), which coincides with the increased expression of anti-inflammatory mediators, this provides a link between the two processes. By extension, it appears plausible that biofilm growth actively directs the ensuing fibrotic response. Our recent studies in the mouse catheter-associated biofilm infection model demonstrated that infected catheters become rapidly surrounded by a fibrotic capsule composed primarily of type I collagen and fibronectin (Hanke and Kielian, in revision). The coating of artificial surfaces and implanted medical devices with platelets and host ECM proteins, such as fibronectin, facilitate S. aureus adherence in vitro (Foster, 1996). In terms of coagulasenegative staphylococci, others have reported enhanced adhesion with various plasma proteins, including fibronectin (Herrmann et al., 1988). These interactions are facilitated by the numerous MSCRAMMs that are expressed by $S$. aureus, which have known binding affinity for monomeric collagen and fibronectin (Rivera et al., 2007). However, others have demonstrated that fibronectin and its proteolytic fragments inhibited S. epidermidis adhesion to plastic surfaces (Dunne and Burd, 1993). This might be explained by either the growth phase when bacteria were harvested (since MSCRAMMs are maximally expressed during log phase growth in broth cultures) or the fact that $S$. epidermidis is more adept at binding to inert surfaces compared to $S$. aureus. In this case, coating with exogenous molecules is more dispensable and conceivably, could deter S. epidermidis binding due to charge repulsion, although this remains highly speculative.

As previously mentioned, numerous studies have identified macrophages as a major effector cell in fibrosis (Lupher and Gallatin, 2006). It is now clear that macrophages can be programmed toward distinct activation phenotypes categorized as classical M1 and alternatively activated M2 macrophages (Gordon, 2003; Mantovani et al., 2004). Th1 cytokines, such as IFN- $\gamma$, activate iNOS and proinflammatory cytokine expression in M1 macrophages, leading to their potent antimicrobial activity. Recently, M2 macrophages have been further subdivided into three types, based on the cytokine milieu encountered and the mediators they secrete. M2a represent what the field collectively considers "M2" macrophages, which are driven by IL-4 and IL-13 and are associated with TGF- $\beta$ production and arginase-1 (ARG1) activity, both of which are pro-fibrotic (Munder et al., 1998; Hesse et al., 2001; Gordon, 2003). M2b macrophages are induced following exposure to PAMPs in combination with IL-1 $\beta$ and are typified by their production of IL-10 and select chemokines. M2c macrophages arise from exposure to TGF- $\beta$ and IL-10; however, less is known about their secretory profile. It is important to note that these activation states likely represent a continuum that is influenced by the local inflammatory milieu and importantly, macrophages exhibit plasticity in their ability to adapt to changing microenvironments (Gordon and Taylor, 2005; Martinez et al., 2009; Biswas and Mantovani, 2010). With regard to antibacterial responses and fibrosis, iNOS and arginase- 1 are involved in opposing pathways (Figure 3). Namely, iNOS is proinflammatory and part of a conserved "core host response" to infection, whereas ARG1 is considered anti-inflammatory and drives fibrotic reactions (Benoit et al., 2008). Therefore, the transition of macrophages from an M1 to an M2 phenotype facilitates fibrosis. Future studies are needed to investigate these macrophage populations throughout the course of staphylococcal biofilm infection to elucidate whether a particular type predominates, particularly with regard to the M2a, M2b, and M2c states. In addition, it will be interesting to determine whether differences in macrophage polarization are observed in S. aureus compared to S. epidermidis biofilms, since the former is significantly more invasive and capable of causing systemic disease (Gordon and Lowy, 2008). In this case, one could envision that the fibrotic response may be more extensively developed with $S$. aureus in an attempt to prevent infection dissemination.

\section{ADAPTIVE IMMUNITY AND STAPHYLOCOCCAL BIOFILMS}

Although little information is currently available regarding adaptive immune responses against staphylococcal biofilms, there is great interest in developing a vaccine to prevent biofilm infections. One challenge toward the development of such a vaccine is identifying appropriate immunodominant antigen(s) that are capable of eliciting robust antimicrobial activity. In fact, the failure to find one such an antigen has led many groups to design multivalent vaccines in hopes of inducing antibody-mediated protection (Brady et al., 2011). The efficacy of a quadrivalent 
vaccine consisting of cell wall- and membrane-associated proteins whose expression is increased during $S$. aureus biofilm growth has been recently examined (Brady et al., 2011). Neither the quadrivalent nor monovalent vaccines were effective at clearing S. aureus biofilms in vivo, and only in combination with powerful antibiotic treatment was any effect achieved (Brady et al., 2011). It is reasonable to predict that antibodies may be capable of clearing planktonic bacteria released from the biofilm; however, it seems less likely that antibodies will be effective in neutralizing bacteria deep within the biofilm, since many organisms are embedded within the matrix and not accessible to antibody opsonization. Indeed, even in individuals with excellent cellular and humoral immune reactions, biofilm infections are rarely resolved by the host unless the biofilm itself is physically removed. For this reason, biofilms are typically persistent infections even after repetitive cycles of antibiotic therapy, which is a testament to the powerful array of factors that staphylococci possess to thwart the host immune response. The reader is referred to several recent reviews discussing the challenges facing the development of an anti-biofilm vaccine based on the multi-factorial nature of the obstacles involved from both the biofilm and immune perspectives (Visai et al., 2007; Harro et al., 2010; Ohlsen and Lorenz, 2010; Montanaro et al., 2011).

\section{POINTS FOR FUTURE CONSIDERATIONS}

When considering the host immune response to staphylococcal biofilms, one must take into account several factors. Particularly, the method of biofilm propagation in vitro (i.e., static versus shear flow), in vivo model, type of immune cell population being examined, genetic background when utilizing mouse models, pathogen niche within the host, variability between various staphylococcal isolates, and the type of biofilm formed (protein vs. polysaccharide) can all conceivably influence experimental outcomes. In terms of in vitro biofilm propagation, the compatibility of medium formulations to achieve optimal survival of both the biofilm and immune cells must be considered. Although typical bacterial broth formulations induce robust biofilm growth, they are likely to induce immune cell apoptosis as we have observed (Figure 5). Although biofilm maturation was slightly delayed in mammalian cell culture medium compared to equivalent growth periods in TSB, biofilms still achieved a relatively uniform thickness and density, along with the presence of tower structures (Thurlow et al., 2011). In addition, it might be argued that this medium formulary may better model the host environment that the bacteria must colonize to establish a biofilm.

Intercellular adhesive mechanisms play a key role in biofilm development, particularly for S. epidermidis biofilms (Heilmann et al., 1996; Cramton et al., 1999; Rohde et al., 2007). PIA was among the first factors identified for mediating biofilm accumulation in S. epidermidis and was later described in S. aureus (Rohde et al., 2007). Recently the surfactant-like PSM peptides have been identified as contributors to $S$. epidermidis and S. aureus biofilm formation and maturation (Wang et al., 2011; Periasamy et al., 2012). Proteins have also been found to play an important role in staphylococcal biofilm formation and in S. epidermidis. Aap was identified as a PIA-independent intercellular adhesin (Rohde et al., 2005; Sun et al., 2005). Likewise, PIA-independent S. aureus

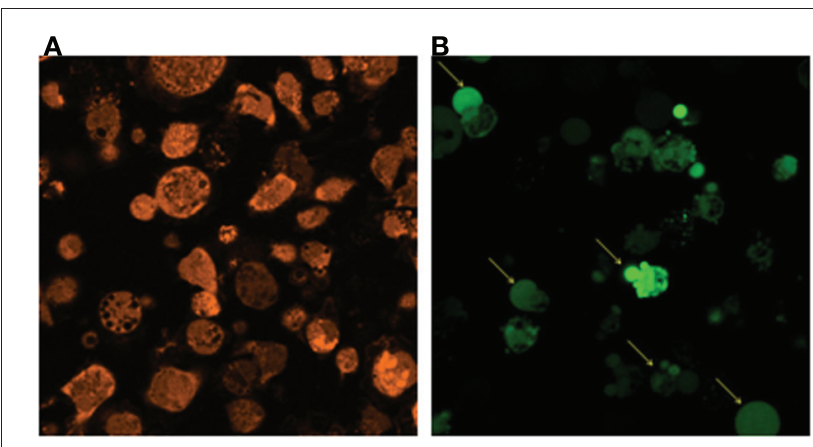

FIGURE 5 | TSB medium does not support macrophage survival.

(A) Primary thioglycollate-elicited peritoneal macrophages isolated from C57BL/6 mice were stained with $5 \mu \mathrm{M}$ CellTracker Orange (orange) and incubated in RPMI 1640 supplemented with $10 \%$ FBS for $24 \mathrm{~h}$ at $37^{\circ} \mathrm{C}$. (B) Primary macrophages isolated from GFP transgenic mice were incubated in TSB supplemented with $0.5 \%$ glucose and $3 \% \mathrm{NaCl}$ for $24 \mathrm{~h}$ at $37^{\circ} \mathrm{C}$. Arrows indicate apoptotic macrophages.

biofilms can also form in humans (Fitzpatrick et al., 2005b; Toledo-Arana et al., 2005).

While there is an abundance of information on staphylococcal biofilm mutants in vitro (Mann et al., 2009; Beenken et al., 2010; Kiedrowski et al., 2011) there is limited number of studies characterizing their impact on host immune mechanisms in vivo. Moreover, those studies that do investigate the ability of staphylococcal mutants to establish biofilms in vivo often use outbred or severely immune compromised mouse strains, which may have a significant impact on the results obtained. Indeed, the mouse strain used can greatly influence the experimental outcome and should be thoughtfully considered when designing in vivo experiments. Additional studies are needed to further our understanding of immunity during staphylococcal biofilm infections in multiple clinically relevant models to identify pathways that may be exploited for therapy.

\section{CONCLUSIONS}

Since staphylococcal biofilms represent a serious clinical situation based on the propensity of organisms to detach and colonize new sites of infection (Lowy, 1998; Fätkenheuer et al., 2002), understanding host immune-biofilm dynamics is an important issue that warrants further investigation. Although there is a now a good foundation documenting immune responses to staphylococcal biofilms, much work remains to be done. In particular, relatively little is known regarding mechanisms of neutrophil and macrophage recognition and activation of staphylococcal biofilms and pathways contributing to fibrotic encapsulation of these infections. These issues are of particular importance and may help explain the phenomenon as to why staphylococcal biofilms are recalcitrant to therapy and could conceivably unveil candidate molecules for targeted therapy to augment host immunity to biofilm infections.

\section{ACKNOWLEDGMENTS}

This work was supported by the NIH National Institute of Allergy and Infectious Diseases (NIAID) P01 AI083211 to Tammy Kielian. 


\section{REFERENCES}

Adair-Kirk, T. L., and Senior, R. M. (2008). Fragments of extracellular matrix as mediators of inflammation. Int. J. Biochem. Cell Biol. 40, 1101-1110.

Allesen-Holm, M., Barken, K. B., Yang, L., Klausen, M., Webb, J. S., Kjelleberg, S., Molin, S., Givskov, M., and Tolker-Nielsen, T. (2006). A characterization of DNA release in Pseudomonas aeruginosa cultures and biofilms. Mol. Microbiol. 59, 1114-1128.

Anwar, S., Prince, L. R., Foster, S. J., Whyte, M. K. B., and Sabroe, I. (2009). The rise and rise of Staphylococcus aureus: laughing in the face of granulocytes. Clin. Exp. Immunol. 157, 216-224.

Bauer, S., Kirschning, C. J., Häcker, H., Redecke, V., Hausmann, S., Akira, S. Wagner, H., and Lipford, G. B. (2001). Human TLR9 confers responsiveness to bacterial DNA via species-specific CpG motif recognition. Proc. Natl. Acad. Sci. U.S.A. 98 9237-9242.

Beenken, K. E., Mrak, L. N., Griffin, L. M., Zielinska, A. K., Shaw, L. N., Rice, K. C., Horswill, A. R., Bayles, K. W., and Smeltzer, M. S. (2010). Epistatic relationships between sarA and agr in Staphylococcus aureus biofilm formation. PLoS One 5:e10790. doi: 10.1371/journal.pone.0010790

Benoit, M., Desnues, B., and Mege, J. L. (2008). Macrophage polarization in bacterial infections. J. Immunol. 181, 3733-3739.

Bernthal, N. M., Pribaz, J. R., Stavrakis, A. I., Billi, F., Cho, J. S., Ramos, R. I., Francis, K. P., Iwakura, Y., and Miller, L. S. (2011). Protective role of IL-1 $\beta$ against post-arthroplasty Staphylococcus aureus infection. J. Orthop. Res. 29, 1621-1626.

Bester, E., Kroukamp, O., Wolfaardt, G. M., Boonzaaier, L., and Liss, S. N. (2010). Metabolic differentiation in biofilms as indicated by carbon dioxide production rates. Appl. Environ. Microbiol. 76, 1189-1197.

Biswas, S. K., and Mantovani, A (2010). Macrophage plasticity and interaction with lymphocyte subsets: cancer as a paradigm. Nat. Immunol. 11, 889-896.

Borregaard, N. (2010). Neutrophils, from marrow to microbes. Immunity 33, 657-670.

Bost, K. L., and Clements, J. D. (1997). Intracellular Salmonella dublin induces substantial secretion of the 40-kilodalton subunit of interleukin-12 (IL-12) but minimal secretion of IL-12 as a 70-kilodalton protein in murine macrophages. Infect. Immun. 65, 3186-3192.

Bouhlel, M. A., Derudas, B., Rigamonti, E., Dievart, R., Brozek, J., Haulon, J., Zawadzki, C., Jude, B., Torpier, G., Marx, N., Staels, B., and Chinetti-Gbaguidi, G. (2007). PPARgamma activation primes human monocytes into alternative M2 macrophages with anti-inflammatory properties. Cell Metab. 6, 137-143.

Brady, R. A., O’May, G. A., Leid, J. G. Prior, M. L., Costerton, J. W., and Shirtliff, M. E. (2011). Resolution of Staphylococcus aureus biofilm infection using vaccination and antibiotic treatment. Infect. Immun. 79, 1797-1803.

Brandt, C. M., Sistrunk, W. W., Duffy, M. C., Hanssen, A. D., Steckelberg, J. M., Ilstrup, D. M., and Osmon, D. R. (1997). Staphylococcus aureus prosthetic infection treated with debridement and prosthesis retention. Clin. Infect. Dis. 24, 914-919.

Brogden, K. A. (2005). Antimicrobial peptides: pore formers or metabolic inhibitors in bacteria? Nat. Rev Microbiol. 3, 238-250

Buret, A., Ward, K. H., Olson, M. E. and Costerton, J. W. (1991). An in vivo model to study the pathobiology of infectious biofilms on biomaterial surfaces. J. Biomed. Mater. Res. 25, 865-874.

Burger, R. R., Basch, T., and Hopson, C. N. (1991). Implant salvage in infected total knee arthroplasty. Clin. Orthop. 273, 105-111.

Cassat, J. E., Lee, C. Y., and Smeltzer, M. S. (2007). Investigation of biofilm formation in clinical isolates of Staphylococcus aureus. Methods Mol. Biol. 391, 127-144.

Cassatella, M. A. (1995). The production of cytokines by polymorphonuclear neutrophils. Immunol. Today 16, 21-26.

Cerca, F., Andrade, F., França, Â. Andrade, E. B., Ribeiro, A. Almeida, A. A., Cerca, N., Pier, G., Azeredo, J., and Vilanova, M. (2011). Staphylococcus epidermidis biofilms with higher proportions of dormant bacteria induce a lower activation of murine macrophages. J. Med. Microbiol. 60, 1717-1724.

Cerca, N., Jefferson, K. K., Oliveira, R., Pier, G. B., and Azeredo, J. (2006) Comparative antibody-mediated phagocytosis of Staphylococcus epidermidis cells grown in a biofilm or in the planktonic state. Infect. Immun. 74, 4849-4855.

Chandra, J., McCormick, T. S., Imamura, Y., Mukherjee, P. K., and Ghannoum, M. A. (2007). Interaction of Candida albicans with adherent human peripheral blood mononuclear cells increases C. albicans biofilm formation and results in differential expression of pro- and anti-inflammatory cytokines. Infect. Immun. 75, 2612-2620.

Clark, L. A., and Easmon, C. S. (1986). Opsonic requirements of Staphylococcus epidermidis. J. Med. Microbiol. 22, 1-7.

Costerton, J. W., Stewart, P. S., and Greenberg, E. P. (1999). Bacterial biofilms: a common cause of persistent infections. Science 284, 1318-1322.

Cramton, S. E., Gerke, C., Schnell, N. F., Nichols, W. W., and Götz, F. (1999). The intercellular adhesion (ica) locus is present in Staphylococcus aureus and is required for biofilm formation. Infect. Immun. 67, 5427-5433.

Craven, R. R., Gao, X., Allen, I. C. Gris, D., Bubeck Wardenburg, J., McElvania-Tekippe, E. Ting, J. P., and Duncan, J. A. (2009). Staphylococcus aureus alpha-hemolysin activates the NLRP3-inflammasome in human and mouse monocytic cells. PLoS One 4:e7446. doi: 10.1371/journal pone. 0007446

Dean, S. N., Bishop, B. M., and van Hoek, M. L. (2011). Natural and synthetic cathelicidin peptides with anti-microbial and anti-biofilm activity against Staphylococcus aureus. BMC Microbiol. 11, 114.

Deininger, S., Stadelmaier, A., von Aulock, S., Morath, S., Schmidt R. R., and Hartung, T. (2003) Definition of structural prerequisites for lipoteichoic acid-inducible cytokine induction by synthetic derivatives. J. Immunol. 170, 4134-4138.

Donlan, R. M., and Costerton, J. W. (2002). Biofilms: survival mechanisms of clinically relevant microorganisms. Clin. Microbiol. Rev. 15, 167-193.

Dornand, J., Gross, A., Lafont, V., Liautard, J., Oliaro, J., and Liautard, J. P. (2002). The innate immune response against Brucella in humans. Vet. Microbiol. 90, 383-394.

Duch, J. M., and Yee, J. (2001). Successful use of recombinant tissue plasminogen activator in a patient with relapsing peritonitis. Am. J. Kidney Dis. 37, 149-153.

Dunne, W. M., and Burd, E. M. (1993). Fibronectin and proteolytic fragments of fibronectin interfere with the adhesion of Staphylococcus epidermidis to plastic. J. Appl. Bacteriol. 74, 411-416.
Dziarski, R. (2003). Recognition of bacterial peptidoglycan by the innate immune system. Cell. Mol. Life Sci. $60,1793-1804$

Dziarski, R., and Gupta, D. (2005). Staphylococcus aureus peptidoglycan is a toll-like receptor 2 activator: a reevaluation. Infect. Immun. 78, 5212-5216.

El-Helou, O., Berbari, E. F., Brown, R. A., Gralewski, J. H., Osmon, D. R., and Razonable, R. R. (2011). Functional assessment of Toll-like receptor 2 and its relevance in patients with Staphylococcus aureus infection of joint prosthesis. Hum. Immunol. 72, 47-53.

Fätkenheuer, G., Cornely, O., and Seifert, H. (2002). Clinical management of catheter-related infections. Clin. Microbiol. Infect. 8, 545-550.

Fey, P. D. (2010). Modality of bacterial growth presents unique targets: how do we treat biofilm-mediated infections? Curr. Opin. Microbiol. 13, 610-615.

Finlay, B. B., and McFadden, G. (2006). Anti-immunology: evasion of the host immune system by bacterial and viral pathogens. Cell 124 767-782.

Fitzpatrick, F., Humphreys, H., and O'Gara, J. P. (2005a). The genetics of staphylococcal biofilm formationwill a greater understanding of pathogenesis lead to better management of device-related infection? Clin. Microbiol. Infect. 11, 967-973.

Fitzpatrick, F., Humphreys, H., and O'Gara, J. P. (2005b). Evidence for icaADBCindependent biofilm development mechanism in methicillin-resistant Staphylococcus aureus clinical isolates. J. Clin. Microbiol. 43, 1973-1976.

Fitzsimmons, K., Bamber, A., and Smalley, H. B. (2010). Infective endocarditis: changing aetiology of disease. Br. J. Biomed. Sci. 67, 35-41.

Flemming, H. C., and Wingender, J (2010). The biofilm matrix. Nat Rev. Microbiol. 8, 623-633.

Foster, T. J. (1996). "Staphylococcus," in Medical Microbiology, ed S. Baron (Galveston, TX: University of Texas Medical Branch at Galveston).

Fournier, B., and Philpott, D. J. (2005). Recognition of Staphylococcus aureus by the innate immune system. Clin. Microbiol. Rev. 18, 521-540.

Fredheim, E. G., Granslo, H. N. Flægstad, T., Figenschau, Y., Rohde, H., Sadovskaya, I., Mollnes, T. E., and Klingenberg, C. (2011). Staphylococcus epidermidis polysaccharide intercellular adhesin activates complement. FEMS Immunol. Med. Microbiol. 63, 269-280. 
Furze, R. C., and Rankin, S. M. (2008). The role of the bone marrow in neutrophil clearance under homeostatic conditions in the mouse. FASEB J. 22, 3111-3119.

Fuxman Bass, J. I., Russo, D. M., Gabelloni, M. L., Geffner, J. R., Giordano, M., Catalano, M., Zorreguieta, A., and Trevani, A. S. (2010). Extracellular DNA: a major proinflammatory component of Pseudomonas aeruginosa biofilms. J. Immunol. 184, 6386-6395.

Gallardo-Soler, A., Gomez-Nieto, C., Campo, M. L., Marathe, C., Tontonoz, P., Castrillo, A., and Corraliza, I. (2008). Arginase I induction by modified lipoproteins in macrophages: a peroxisome proliferator-activated receptor\{gamma\}/\{delta\}-mediated effect that links lipid metabolism and immunity. Mol. Endocrinol. 22, 1394-1402.

Garvin, K. L., and Hanssen, A. D. (1995). Infection after total hip arthroplasty. J. Bone Joint Surg. Am. 77, 1576-1588.

Girardin, S. E., Boneca, I. G., Viala, J., Chamaillard, M., Labigne, A., Thomas, G., Philpott, D. J., and Sansonetti, P. J. (2003). Nod2 is a general sensor of peptidoglycan through muramyl dipeptide (MDP) detection. J. Biol. Chem. 278, 8869-8872.

Gonzalez-Mejia, M. E., and Doseff, A. I. (2009). Regulation of monocytes and macrophages cell fate. Front. Biosci. 14, 2413-2431.

Gordon, R. J., and Lowy, F. D. (2008). Pathogenesis of methicillinresistant Staphylococcus aureus infection. Clin. Infect. Dis. 46, S350-S359.

Gordon, S. (2003). Alternative activation of macrophages. Nat. Rev. Immunol. 3, 23-35.

Gordon, S., and Taylor, P. R. (2005). Monocyte and macrophage heterogeneity. Nat. Rev. Immunol. 5, 953-964.

Graham, D. B., Robertson, C. M., Bautista, J., Mascarenhas, F., Diacovo, M. J., Montgrain, V., Lam, S. K., Cremasco, V., Dunne, W. M., Faccio, R., Coopersmith, C. M., and Swat, W. (2007). Neutrophilmediated oxidative burst and host defense are controlled by a Vav-PLCgamma2 signaling axis in mice. J. Clin. Invest. 117, 3445-3452.

Graves, S. F., Kobayashi, S. D., and DeLeo, F. R. (2010). Communityassociated methicillin-resistant Staphylococcus aureus immune evasion and virulence. J. Mol. Med. (Berl.) 88, 109-114.
Guenther, F., Stroh, P., Wagner, C., Obst, U., and Hänsch, G. M. (2009). Phagocytosis of staphylococci biofilms by polymorphonuclear neutrophils: S. aureus and S. epidermidis differ with regard to their susceptibility towards the host defense. Int. J. Artif. Organs 32, 565-573.

Günther, F., Wabnitz, G. H., Stroh, P., Prior, B., Obst, U., Samstag, Y., Wagner, C., and Hänsch, G. M. (2009). Host defence against Staphylococcus aureus biofilms infection: phagocytosis of biofilms by polymorphonuclear neutrophils (PMN). Mol. Immunol. 46, 1805-1813.

Hajjar, A. M., O’Mahony, D. S., Ozinsky, A., Underhill, D. M., Aderem, A., Klebanoff, S. J., and Wilson, C. B. (2001). Cutting edge: functional interactions between toll-like receptor (TLR) 2 and TLR1 or TLR6 in response to phenolsoluble modulin. J. Immunol. 166, 15-19.

Hanamsagar, R., Torres, V., and Kielian, T. (2011). Inflammasome activation and IL-1 $\beta / \mathrm{IL}-18$ processing are influenced by distinct pathways in microglia. J. Neurochem. 119, 736-748.

Harro, J. M., Peters, B. M., O’May, G. A., Archer, N., Kerns, P., Prabhakara, R., and Shirtliff, M. E. (2010). Vaccine development in Staphylococcus aureus: taking the biofilm phenotype into consideration. FEMS Immunol. Med. Microbiol. 59, 306-323.

Hartman, M. B., Fehring, T. K., Jordan, L., and Norton, H. J. (1991) Periprosthetic knee sepsis. The role of irrigation and debridement. Clin. Orthop. Relat. Res. 273, 113-118.

Hashimoto, M., Tawaratsumida, K., Kariya, H., Aoyama, K., Tamura, T., and Suda, Y. (2006a). Lipoprotein is a predominant Toll-like receptor 2 ligand in Staphylococcus aureus cell wall components. Int. Immunol. 18, 355-362.

Hashimoto, M., Tawaratsumida, K., Kariya, H., Kiyohara, A., Suda, Y., Krikae, F., Kirikae, T., and Götz, F. (2006b). Not lipoteichoic acid but lipoproteins appear to be the dominant immunobiologically active compounds in Staphylococcus aureus. J. Immunol. 177 , 3162-3169.

Hayashi, F., Means, T. K., and Luster, A. D. (2003). Toll-like receptors stimulate human neutrophil function. Blood 102, 2660-2669.

Heilmann, C., Schweitzer, O., Gerke, C., Vanittanakom, N., Mack, D., and Götz, F. (1996). Molecular basis of intercellular adhesion in the biofilm-forming Staphylococcus epidermidis. Mol. Microbiol. 20 1083-1091.

Hemmi, H., Takeuchi, O., Kawai, T., Kaisho, T., Sato, S., Sanjo, H., Matsumoto, M., Hoshino, K. Wagner, H., Takeda, K., and Akira S. (2000). A Toll-like receptor recognizes bacterial DNA. Nature 408, 740-745.

Herrmann, M., Vaudaux, P. E., Pittet, D., Auckenthaler, R., Lew, P. D., Schumacher-Perdreau, F. Peters, G., and Waldvogel, F. A (1988). Fibronectin, fibrinogen, and laminin act as mediators of adherence of clinical staphylococcal isolates to foreign material. J. Infect. Dis. 158, 693-701.

Hertz, C. J., Kiertscher, S. M., Godowski, P. J., Bouis, D. A., Norgard, M. V., Roth, M. D., and Modlin, R. L. (2001). Microbial lipopeptides stimulate dendritic cell maturation via Toll-like receptor 2 . J. Immunol. 166, 2444-2450.

Hesse, M., Modolell, M., La Flamme, A. C., Schito, M., Fuentes, J. M. Cheever, A. W., Pearce, E. J., and Wynn, T. A. (2001). Differential regulation of nitric oxide synthase2 and arginase- 1 by type 1/type 2 cytokines in vivo: granulomatous pathology is shaped by the pattern of L-arginine metabolism. J. Immunol. 167, 6533-6544.

Hoiby, N., Fomsgaard, A., Jensen, E. T., Johansen, H. K., Kronborg, G. Pedersen, S. S., Pressler, T., and Kharazmi, A. (1995). The Immune Response to Bacterial Biofilms. Cambridge, United Kingdom, MA Cambridge University Press

Hornung, V., and Latz, E. (2010) Intracellular DNA recognition. Nat. Rev. Immunol. 10, 123-130.

Jensen, E. T., Kharazmi, A., Lam, K., Costerton, J. W., and Hoiby, N. (1990). Human polymorphonuclear leukocyte response to Pseudomonas aeruginosa grown in biofilms. Infect. Immun. 58, 2383-2385.

Jesaitis, A. J., Franklin, M. J., Berglund, D., Sasaki, M., Lord, C. I., Bleazard, J. B., Duffy, J. E., Beyenal, H., and Lewandowski, Z. (2003). Compromised host defense on Pseudomonas aeruginosa biofilms: characterization of neutrophil and biofilm interactions. J. Immunol. 171, 4329-4339.

Jones, B. W., Means, T. K., Heldwein, K. A., Keen, M. A., Hill, P. J., Belisle, J. T., and Fenton, M. J. (2001). Different Toll-like receptor agonists induce distinct macrophage responses. J. Leukoc. Biol. 69 1036-1044.
Kaisho, T., and Akira, S. (2004). Pleiotropic function of Toll-like receptors. Microbes Infect. 6, 1388-1394.

Kawai, T., and Akira, S. (2011). Tolllike receptors and their crosstalk with other innate receptors in infection and immunity. Immunity 34, 637-650.

Kiedrowski, M. R., Kavanaugh, J. S., Malone, C. L., Mootz, J. M., Voyich, J. M., Smeltzer, M. S., Bayles, K. W., and Horswill, A. R. (2011). Nuclease modulates biofilm formation in community-associated methicillin-resistant Staphylococcus aureus. PLoS One 6:e26714. doi 10.1371/journal.pone.0026714

Kirschning, C. J., and Schumann, R. R. (2002). TLR2, cellular sensor for microbial and endogenous molecular patterns. Curr. Top. Microbiol. Immunol. 270, 121-144.

Kobayashi, S. D., Braughton, K. R., Whitney, A. R., Voyich, J. M., Schwan, T. G., Musser, J. M. and DeLeo, F. R. (2003). Bacterial pathogens modulate an apoptosis differentiation program in human neutrophils. Proc. Natl. Acad. Sci. U.S.A. 100, 10948-10953.

Kopp, E., and Medzhitov, R. (2003). Recognition of microbial infection by Toll-like receptors. Curr. Opin. Immunol. 15, 396-401.

Korpos, E., Wu, C., and Sorokin, L. (2009). Multiple roles of the extracellular matrix in inflammation. Curr. Pharm. Des. 15, 1349-1357.

Kristian, S. A., Birkenstock, T. A., Sauder, U., Mack, D., Götz, F., and Landmann, R. (2008). Biofilm formation induces $\mathrm{C} 3 \mathrm{a}$ release and protects Staphylococcus epidermidis from IgG and complement deposition and from neutrophildependent killing. J. Infect. Dis. 197, 1028-1035.

Kurokawa, K., Lee, H., Roh, K. B., Asanuma, M., Kim, Y. S., Nakayama, H., Shiratsuchi, A., Choi, Y., Takeuchi, O., Kang, H. J., Dohmae, N., Nakanishi, Y., Akira, S., Sekimizu, K., and Lee, B. L. (2009). The triacylated ATP binding cluster transporter substrate-binding lipoprotein of Staphylococcus aureus functions as a native ligand for toll-like receptor 2 . J. Biol. Chem. 284, 8406-8411.

Leid, J. G., Shirtliff, M. E., Costerton, J. W., and Stoodley, P. (2002). Human leukocytes adhere to, penetrate, and respond to Staphylococcus aureus biofilms. Infect. Immun. 70, 6339-6345.

Lew, D. P., and Waldvogel, F. A. (1997) Osteomyelitis. N. Engl. J. Med. 326, 999-1007. 
Lopez-Leban, F., Kiran, M. D., Wolcott, R., and Balaban, N. (2010). Molecular mechanisms of RIP, an effective inhibitor of chronic infections. Int. J. Artif. Organs 33, 582-589.

Lowy, F. D. (1998). Staphylococcus aureus infections. N. Engl. J. Med. 339, 520-532.

Lupher, M. L. Jr., and Gallatin, W. M. (2006). Regulation of fibrosis by the immune system. Adv. Immunol. 89, 245-288.

Mann, E. E., Rice, K. C., Boles, B. R., Endres, J. L., Ranjit, D., Chandramohan, L., Tsang, L. H. Smeltzer, M. S., Horswill, A. R., and Bayles, K. W. (2009). Modulation of eDNA release and degradation affects Staphylococcus aureus biofilm maturation. PloS One 4:e5822 doi: 10.1371/journal.pone.0005822

Mahdavian Delavary, B., vander Veer, W. M., van Egmond, M., Niessen, F. B., and Beelen, R. H. (2011). Macrophages in skin injury and repair. Immunnobiology 216, 753-762.

Mantovani, A., Cassatella, M. A., Costantini, C., and Jaillon, S. (2011). Neutrophils in the activation and regulation of innate and adaptive immunity. Nat. Rev. Immunol. 11, 519-531.

Mantovani, A., Sica, A., Sozzani, S., Allavena, P., Vecchi, A., and Locati, M. (2004). The chemokine system in diverse forms of macrophage activation and polarization. Trends Immunol. 25, 677-689.

Martinez, F. O., Helming, L., and Gordon, S. (2009). Alternative activation of macrophages: an immunologic functional perspective. Annu. Rev. Immunol. 27, 451-483.

Mauviel, A. (2005). Transforming growth factor-beta: a key mediator of fibrosis. Methods Mol. Med. 117, 69-80.

Medzhitov, R. (2007). Recognition of microorganisms and activation of the immune response. Nature 449 , 819-826.

Medzhitov, R., and Janeway, C. Jr. (2000). Innate immunity. N. Engl. J. Med. 345, 338-344.

Menousek, J., Mishra, B., Hanke, M. L., Heim, C. E., Kielian, T., and Wang, G. (2012). Database screening and in vivo efficacy of antimicrobial peptides against meticillin-resistant Staphylococcus aureus USA300. Int. J. Antimicrob. Agents 39, 402-406.

Mercier, C., Durrieu, C., Briandet, R., Domakova, E., Tremblay, J., Buist, G., and Kulakauskas, S. (2002). Positive role of peptidoglycan breaks in lactococcal biofilm formation. Mol. Microbiol. 46, 235-243.

Meyle, E., Stroh, P., Günther, F., HoppyTichy, T., Wagner, C., and Hänsch, G. M. (2010). Destruction of bacterial biofilms by polymorphonuclear neutrophils: relative contribution of phagocytosis, DNA release, and degranulation. Int. J. Artif. Organs $33,608-620$.

Montanaro, L., Speziale, P., Campoccia, D., Ravaioli, S., Cangini, I., Pietrocola, G., Giannini, S., and Arciola, C. R. (2011). Scenery of Staphylococcus implant infections in orthopedics. Future Microbiol. 6, 1329-1349.

Morath, S., Stadelmaier, A., Geyer, A., Schmidt, R. R., and Hartung. T. (2002). Synthetic lipoteichoic acid from Staphylococcus aureus is a potent stimulus of cytokine release. J. Exp. Med. 195, 1635-1640.

Morscher, E., Herzog, R., Bapst, R., and Zimmerli, W. (1995). Management of infected hip arthroplasty. Orthop. Int. 3, 343-351.

Moscoso, M., Garcia, E., and Lopez, R. (2006). Biofilm formation by Streptococcus pneumoniae: role of choline, extracellular DNA, and capsular polysaccharide in microbial accretion. J. Bacteriol. 188, 7785-7795.

Mullaly, S. C., and Kubes, P. (2006). The role of TLR2 in vivo following challenge with Staphylococcus aureus and prototypic ligands. J. Immunol. 177, 8154-8163.

Munder, M., Eichmann, K., and Modolell, M. (1998). Alternative metabolic states in murine macrophages reflected by the nitric oxide synthase/arginase balance: competitive regulation by $\mathrm{CD} 4+\mathrm{T}$ cells correlates with Th1/Th2 phenotype. J. Immunol. 160, 5347-5354.

Nathan, C. (2006). Neutrophils and immunity: challenges and opportunities. Nat. Rev. Immunol. 6, 173-182.

Nauseef, W. M. (2007). How human neutrophils kill and degrade microbes: an integrated view. Immunol. Rev. 219, 88-102.

O'Neill, L. A. (2004). TLRs: Professor Mechnikov, sit on your hat. Trends Immunol. 25, 687-693.

Ohlsen, K., and Lorenz, U. (2010). Immunotherapeutic strategies to combat staphylococcal infections. Int. J. Med. Microbiol. 300, 402-410.

Otto, M. (2008). Staphylococcal biofilms. Curr. Top. Microbiol. Immunol. 322, 207-228.

Pathak, S. K., Basu, S., Basu, K. K., Banerjee, A., Pathak, S.,
Bhattacharyya, A., Kaisho, T., Kundu, M., and Basu, J. (2007). Direct extracellular interaction between the early secreted antigen ESAT-6 of Mycobacterium tuberculosis and TLR2 inhibits TLR signaling in macrophages. Nat. Immunol. 8, 610-618.

Periasamy, S., Joo, H. S., Duong, A. C., Bach, T. H., Tan, V. Y., Chatterjee, S. S., Cheung, G. Y., and Otto, M. (2012). How Staphylococcus aureus biofilms develop their characteristic structure. Proc. Natl. Acad. Sci. U.S.A. 109, 1281-1286.

Pickering, S. J., Fleming, S. J., Bowley, J. A., Sissons, P., Oppenheim, B. A., Burnie, J., Ralston, A. J., and Ackrill, P. (1989). Urokinase: a treatment for relapsing peritonitis due to coagulase-negative staphylococci. Nephrol. Dial. Transplant 4 62-65.

Prabhakara, R., Harro, J. M., Leid, J. G., Harris, M., and Shirtliff, M. E. (2011). Murine immune response to a chronic Staphylococcus aureus biofilm infection. Infect. Immun. 79, 1789-1796.

Qin, Z., Ou, Y., Yang, L., Zhu, Y., Tolker-Nielsen, T., Molin, S., and $\mathrm{Qu}, \mathrm{D}$. (2007). Role of autolysinmediated DNA release in biofilm formation of Staphylococcus epidermidis. Microbiology 153, 2083-2092.

Rahman, M. M., and McFadden, G. (2011). Modulation of NF- $\mathrm{BB}$ signalling by microbial pathogens. Nat. Rev. Microbiol. 9, 291-306.

Replacement, N. C. D. P. O. T. H (1995). Total hip replacement. JAMA 273, 1950-1956.

Rasul, A. T. Jr., Tsukayama, D., and Gustilo, R. B. (1991). Effect of time on onset and depth of infection on the outcome of total knee arthroplasty infections. Clin. Orthop. 273 98-103.

Rice, K. C., Mann, E. E., Endres, J. L., Weiss, E. C., Cassat, J. E. Smeltzer, M. S., and Bayles, K. W. (2007). The cidA murein hydrolase regulator contributes to DNA release and biofilm development in Staphylococcus aureus. Proc. Natl Acad. Sci. U.S.A. 104, 8113-8118.

Rivera, J., Vannakambadi, G., Höök, M., and Speziale, P. (2007). Fibrinogen-binding proteins of Gram-positive bacteria. Thromb Haemost. 98, 503-511.

Rodero, M. P., and Khosrotehrani, K. (2010). Skin wound healing modulation by macrophages. Int. J. Clin. Exp. Pathol. 3, 643-653.

Rohde, H., Burandt, E. C., Siemssen, N., Frommelt, L., Burdelski, C., Wurster, S., Scherpe, S., Davies,
A. P., Harris, L. G., Horstkotte, M. A., Knobloch, J. K., Ragunath, C., Kaplan, J. B., and Mack, D. (2007). Polysaccharide intercellular adhesin or protein factors in biofilm accumulation of Staphylococcus epidermidis and Staphylococcus aureus isolated from prosthetic hip and knee joint infections. Biomaterials 28, 1711-1720.

Rohde, H., Burdelski, C., Bartscht, K., Hussain, M., Buck, F., Horstkotte, M. A., Knobloch, J. K., Heilmann, C., Herrmann, M., and Mack, D (2005). Induction of Staphylococcus epidermidis biofilm formation via proteolytic processing of the accumulation-associated protein by staphylococcal and host proteases. Mol. Microbiol. 55, 1883-1895.

Rupp, M. E., Ulphani, J. S., Fey, P. D., Bartscht, K., and Mack, D. (1999). Characterization of the importance of polysaccharide intercellular adhesin/hemagglutinin of Staphylococcus epidermidis in the pathogenesis of biomaterial-based infection in a mouse foreign body infection model. Infect. Immun. 67, 2627-2632.

Schoifet, S. D., and Morrey, B. F. (1990). Treatment of infection after total knee arthroplasty by de'bridement with retention of the components. J. Bone Joint Surg. Am. 72, 1383-1390.

Schommer, N. N., Christner, M., Hentschke, M., Ruckdeschel, K., Aepfelbacher, M., and Rohde, H. (2011). Staphylococcus epidermidis uses distinct mechanisms of biofilm formation to interfere with phagocytosis and activation of mouse macrophage-like cells 774A.1. Infect. Immun. 79, 2267-2276.

Schroder, K., and Tschopp, J. (2010). The inflammasomes. Cell 140, 821-832.

Serbina, N. V., Jia, T., Hohl, T. M. and Pamer, E. G. (2008). Monocytemediated defense against microbial pathogens Annu. Rev. Immunol. 26, $421-452$.

Silva, M. T. (2010). When two is better than one: macrophages and neutrophils work in concert in innate immunity as complementary and cooperative partners of a myeloid phagocyte system. J. Leukoc. Biol. 87, 93-106.

Silva, M. T. (2011). Macrophage phagocytosis of neutrophils at inflammatory/infectious foci: a cooperative mechanism in the control of infection and infectious inflammation. J. Leukoc. Biol. 89, 675-683.

Singh, R., Ray, P., Das, A., and Sharma, M. (2010). Penetration of antibiotics through Staphylococcus aureus and 
Staphylococcus epidermidis biofilms. J. Antimicrob. Chemother. 65, 1955-1958.

Sorokin, L. (2010). The impact of the extracellular matrix on inflammation. Nat. Rev. Immunol. 10, 712-723.

Spormann, A. M. (2008). Physiology of Microbes in Biofilms. Springer: Berlin, Germany.

Stevens, N. T., Sadovskaya, I., Jabbouri, S., Sattar, T., O'Gara, J. P., Humphreys, H., and Greene, C. M. (2009). Staphylococcus epidermidis polysaccharide intercellular adhesin induces IL-8 expression in human astrocytes via a mechanism involving TLR2. Cell Microbiol. 11, 421-432.

Stewart, P. S., and Costerton, J. W. (2001). Antibiotic resistance of bacteria in biofilms. Lancet 258, 135-138.

Stewart, P. S., and Franklin, M. J. (2008). Physiological heterogeneity in biofilms. Nat. Rev. Microbiol. 6, 199-210.

Strunk, T., Power Coombs, M. R., Currie, A. J., Richmond, P., Golenbock, D. T., Stoler-Barak, L., Gallington, L. C., Otto, M., Burgner, D., and Levy, O. (2010). TLR2 mediates recognition of live Staphylococcus epidermidis and clearance of bacteremia. PLoS One 5, e10111. doi: 10.1371/journal.pone.0010111

Sun, D., Accavitti, M. A., and Bryers, J. D. (2005). Inhibition of biofilm formation by monoclonal antibodies against Staphylococcus epidermidis RP62A accumulation-associated protein. Clin. Diagn. Lab Immunol. 12, 93-100.

Takeuchi, O., Hoshino, K., and Akira, S. (2000). Cutting edge: TLR2deficient and MyD88-deficient mice are highly susceptible to Staphylococcus aureus infection. J. Immunol. 165, 5392-5396.

Takeuchi, O., Hoshino, K., Kawai, T., Sanjo, H., Takada, H., Ogawa, T., Takeda, K., and Akira, S. (1999). Differential roles of TLR2 and TLR4 in recognition of gramnegative and gram-positive bacterial cell wall components. Immunity 11 , 443-451.

Thurlow, L. R., Hanke, M. L., Fritz, T., Angle, A., Williams, S. H.,
Engebretsen, I. L., Bayles, K. W., Horswill, A. R., and Kielian, T. (2011). Staphylococcus aureus biofilms prevent macrophage phagocytosis and attenuate inflammation in vivo. J. Immunol. 186, 6585-6596.

Toledo-Arana, A., Merino, N., VergaraIrigaray, M., Debarbouille, M. Penades, J. R., and Lasa, I. (2005). Staphylococcus aureus develops an alternative, ica-independent biofilm in the absence of the arlRS two-component system. J. Bacteriol. 187, 5318-5329.

Travassos, L. H., Girardin, S. E., Philpott, D. J., Blanot, D., Nahori, M. A., Werts, C., and Boneca, I. G. (2004). Toll-like receptor 2-dependent bacterial sensing does not occur via peptidoglycan recognition. $E M B O$ Rep. 5, 1000-1006.

Tsukayama, D. T., Wicklund, B., and Gustilo, R. B. (1991). Suppressive antibiotic therapy in chronic prosthetic joint infections. Orthopedics $14,841-844$.

Vazquez-Torres, A., Xu, Y., JonesCarson, J., Holden, D. W., Lucia, S. M., Dinauer, M. C., Mastroeni, P., and Fang, F. C. (2000). Salmonella pathogenicity island 2-dependent evasion of the phagocyte NADPH oxidase. Science 287, 1655-1658.

Vilaysane, A., and Muruve, D. A. (2009). The innate immune response to DNA. Semin. Immunol. 21, 208-214.

Visai, L., Arciola, C. R., Pietrocola, G., Rindi, S., Olivero, P., and Speziale, P. (2007). Staphylococcus biofilm components as targets for vaccines and drugs. Int. J. Artif. Organs 30, 813-819.

Volz, T., Nega, M., Buschmann, J., Kaesler, S., Guenova, E., Peschel, A., Röcken, M., Götz, F., and Biedermann, T. (2010). Natural Staphylococcus aureus-derived peptidoglycan fragments activate NOD2 and act as potent costimulators of the innate immune system exclusively in the presence of TLR signals. FASEB J. 10, 4089-4102.

Wagner, C., Aytac, S., and Hänsch, G. M. (2011). Biofilm growth on implants: bacteria prefer plasma coats. Int. J. Artif. Organs 34, 811-817.
Wagner, C., Kondella, K., Bernschneider, T., Heppert, V., Wentzensen, A., and Hänsch, G. M (2003). Post-traumatic osteomyelitis: analysis of inflammatory cells recruited into the site of infection. Shock 20, 503-510.

Wagner, C., Obst, U., and Hänsch, G. M. (2005). Implant-associated posttraumatic osteomyelitis: collateral damage by local host defense? Int. J. Artif. Organs 28 1172-1180.

Walker, T. S., Tomlin, K. L., Worthen, G. S., Poch, K. R., Lieber, J. G., Saavedra, M. T., Fessler, M. B., Malcolm, K. C., Vasil, M. L., and Nick, J. A. (2005). Enhanced Pseudomonas aeruginosa biofilm development mediated by human neutrophils. Infect. Immun. 73 3693-3701.

Wang, R., Khan, B. A., Cheung, G Y., Bach, T. H., Jameson-Lee, M. Kong, K. F., Queck, S. Y., and Otto, M. (2011). Staphylococcus epidermidis surfactant peptides promote biofilm maturation and dissemination of biofilm-associated infection in mice. J. Clin. Invest. 121 238-248.

Weber, J. R., Moreillon, P., and Tuomanen, E. I. (2003). Innate sensors for Gram positive bacteria. Curr. Opin. Immunol. 15, 408-415.

Whitchurch, C. B., Tolker-Nielsen, T., Ragas, P. C., and Mattick, J. S. (2002). Extracellular DNA required for bacterial biofilm formation. Science 295, 1487.

Wight, T. N., and Potter-Perigo, S (2011). The extracellular matrix: an active or passive player in fibrosis? Am. J. Physiol. Gastrointest. Liver Physiol. 301, G950-G955.

Wilson, M. G., Kelley, K., and Thornhill, T. S. (1990). Infection as a complication of total kneereplacement arthroplasty. J. Bone. Joint. Surg. Am. 72, 878-883.

Witko-Sarsat, V., Rieu, P., DescampsLatscha, B., Lesavre, P., and Halbwachs-Mecarelli, L. (2000). Neutrophils: molecules, functions and pathophysiological aspects. Lab. Invest. 80, 617-653.

Wynn, T. A. (2004). Fibrotic disease and the $\mathrm{T}(\mathrm{H}) 1 / \mathrm{T}(\mathrm{H}) 2$ paradigm. Nat. Rev. Immunol. 4, 583-594.
Wynn, T. A. (2008). Cellular and molecular mechanisms of fibrosis. J. Pathol. 214, 199-210.

Xu, K. D., McFeters, G. A., and Stewart, P. S. (2000). Biofilm resistance to antimicrobial agents. Microbiology $146,547-549$.

Yamashiro, S., Kamohara, H., Wang, J. M., Yang, D., Gong, W. H., and Yoshimura, T. (2001). Phenotypic and functional change of cytokineactivated neutrophils: inflammatory neutrophils are heterogeneous and enhance adaptive immune responses. J. Leukoc. Biol. 69 698-704.

Yeaman, M. R., and Yount, N. Y. (2003). Mechanisms of antimicrobial peptide action and resistance. Pharmacol. Rev. 55, 27-55.

Yoshimura, A., Lien, E., Ingalls, R. R., Tuomanen, E., Dziarski, R., and Golenbock, D. (1999). Cutting edge: recognition of Gram-positive bacterial cell wall components by the innate immune system occurs via Toll-like receptor 2. J. Immunol. 163, $1-5$.

Zuluaga, A. F., Galvis, W., Saldarriaga, J. G., Agudelo, M., Salazar, B. E. and Vesga, O. (2006). Etiologic diagnosis of chronic osteomyelitis: a prospective study. Arch. Intern. Med. 166, 95-100.

Conflict of Interest Statement: The authors declare that the research was conducted in the absence of any commercial or financial relationships that could be construed as a potential conflict of interest.

Received: 02 February 2012; paper pending published: 09 March 2012; accepted: 20 April 2012; published online: 08 May 2012.

Citation: Hanke ML and Kielian T (2012) Deciphering mechanisms of staphylococcal biofilm evasion of host immunity. Front. Cell. Inf. Microbio. 2:62. doi: 10.3389/fcimb.2012.00062

Copyright (c) 2012 Hanke and Kielian. This is an open-access article distributed under the terms of the Creative Commons Attribution Non Commercial License, which permits non-commercial use, distribution, and reproduction in other forums, provided the original authors and source are credited. 